Article

\title{
Comparison of the Crystal Structure and Wear Resistance of Co-Based Alloys with Low Carbon Content Manufactured by Selective Laser Sintering and Powder Injection Molding
}

\author{
Anna Ziębowicz ${ }^{1}$, Krzysztof Matus ${ }^{2}$ (D), Wojciech Pakieła ${ }^{2}$, Grzegorz Matula ${ }^{2}$ and \\ Miroslawa Pawlyta 2,*(D) \\ 1 Department of Biomaterials and Medical Devices Engineering, Silesian University of Technology, Roosevelt \\ 40 St., 41-800 Zabrze, Poland; anna.ziebowicz@polsl.pl \\ 2 Department of Engineering Materials and Biomaterials, Silesian University of Technology, Konarskiego 18A, \\ 44-100 Gliwice, Poland; krzysztof.matus@polsl.pl (K.M.); wojciech.pakiela@polsl.pl (W.P.); \\ grzegorz.matula@polsl.pl (G.M.) \\ * Correspondence: miroslawa.pawlyta@polsl.pl
}

Received: 31 December 2019; Accepted: 2 March 2020; Published: 13 March 2020

\begin{abstract}
Cobalt alloys are widely used in biomedicine, implantology, and dentistry due to their high corrosion resistance and good mechanical properties. The high carbon improves the wear properties, but causes fragility and dangerous cracking of elements during use. The aim of the present work was to analyze and compare the structure and wear resistance of Co-based alloy samples with low carbon content, produced by Selective Laser Sintering (SLS) and Powder Injection Molding (PIM). Structure characterization, mainly with the use of transmission electron microscopy, was applied to investigate the differences in tribological properties. The better resistance to abrasive wear for SLS was explained by the presence of a hard, intermetallic phase, present as precipitates limited in size and evenly distributed in the cobalt matrix. The second factor was the structure of the cobalt matrix, with dominant content of the hexagonal phase. By combining the characteristic features of the matrix and the reinforcing phase, the analyzed material gains an additional advantage, namely a higher resistance to abrasive wear.
\end{abstract}

Keywords: Co-based alloy; tribological properties; wear; microstructure; selective laser sintering (SLS); powder injection molding (PIM)

\section{Introduction}

The structure of a Co-based alloy consists of a low-temperature phase $\varepsilon$ (hexagonal close-packed (hcp)) and a phase $\gamma$ (face-centered cubic (fcc)), which is formed at a higher temperature. In equilibrium conditions, only the $\varepsilon$ phase exists. However, the $\gamma \rightarrow \varepsilon$ transformation in Co and its alloys is very slow, due to the limited chemical driving forces available at the transformation temperature. Thus, especially at high cooling rates, the transformation is retained below the phase boundary in a metastable state $[1,2]$. It is also worth noting that the reverse transformation $\varepsilon \rightarrow \gamma$ is rare in Co-based alloys, and the $\varepsilon$ phase is much more stable than the $\gamma$ phase at room temperature [3]. The $\gamma \rightarrow \varepsilon$ transformation is associated with the decreasing value of the stacking fault energy [4], and the martensite $\varepsilon$ phase is greatly known to reduce ductility due to the relatively lower number of effective slip systems [5]. Co-based alloys, especially for medical applications, contain added chromium and molybdenum. The purpose of chromium is to increase the corrosion resistance. The role of molybdenum is grain refinement and strengthening of the matrix. In the substructure of Co-based alloys, a significant concentration of 
stacking faults is visible, which results from the low stacking fault energy value. Reducing the density of stacking faults can be achieved by the addition of tungsten [6]. Good wear resistance of cobalt alloys is usually attributed to increased strengthening and formation of carbides or nitrides. In biomedical applications, the carbon content has to be limited, to avoid the risk of the carbides' transformation into a brittle tetragonal intermetallic $\sigma \mathrm{Co}_{7} \mathrm{Cr}_{8}$ phase. Elements manufactured from Co-based alloys with low carbon guarantee safe use (there is no risk of unexpected cracking due to the fragility of the material), but at the same time they wear out faster.

In order to obtain Co-based alloys that are wear-resistant and non-fragile, new dynamically developing production techniques, for example, Selective Laser Sintering (SLS) [7-11], can be applied. SLS deviates from traditional methods of producing materials (e.g., foundry) due to the extreme temperature gradient. After the metal powder has been melted by the laser, the solidification is very fast. Therefore, it is reasonable to expect that alloys produced by SLS will have different properties and a micro/nanostructure compared to alloys that crystallize more slowly. In particular, cobalt-based alloys with homogeneous structure, good mechanical properties, and resistant to wear can be obtained. The second technique also offering such possibilities is Powder Injection Molding (PIM). PIM is a plastic shaping technique applied to powder metallurgy systems [12,13], where a small size powder is used that can be next sintered to full density. The aim of the present work was to analyze and compare the structure and wear resistance of Co-based alloy samples with low carbon content, produced by SLS and PIM.

\section{Materials and Methods}

The specimen produced by the SLS technique was obtained from metal powder (EOS CobaltChrome SP2) with the EOSINT M270 machine (Electro Optical Systems GmbH, Krailling, Germany), using the standard laser sintering parameters (laser power: $200 \mathrm{~W}$; laser spot diameter: $200 \mu \mathrm{m}$; layer thickness: $20 \mu \mathrm{m}$; scan speed: up to $2.0 \mathrm{~m} / \mathrm{s}$ ). The chemical composition of the used powder is presented in Table 1. After additive manufacturing, the material was subjected to a thermal treatment typical of dental applications. Stress relieving thermal treatment was performed under argon atmosphere and consisted of heating to $450^{\circ} \mathrm{C}$ in $60 \mathrm{~min}$, maintaining this temperature for $45 \mathrm{~min}$, heating to $750{ }^{\circ} \mathrm{C}$ in $45 \mathrm{~min}$, and then maintaining this temperature for $60 \mathrm{~min}$. Next, a fire simulation of the ceramic veneering, including five steps, was applied. In each step, the temperature was increased from $450{ }^{\circ} \mathrm{C}$ to about $950^{\circ} \mathrm{C}$ for 5 minutes with vacuum. Subsequently, the material obtained was designated as Co-SLS. For the production of the PIM specimen, a CoCrMo powder with low carbon content $(<0.05 \%)$ was used (Table 1). The powder was mixed with a two-component binder basis on paraffin and the skeleton polymer to produce the feedstock. The homogenized mixture was then injected by a piston injection molding machine into a mold and debinded by a two-step process (thermal degradation followed by solvent degradation in pure heptane at $20-40{ }^{\circ} \mathrm{C}$ ). Thermal debinding was carried out in a flowing gas mixture $\mathrm{Ar}-10 \% \mathrm{H}_{2}$ at the rate of $0.1 \mathrm{~L} / \mathrm{min}$. The samples were sintered at the same atmosphere at a temperature of $1260^{\circ} \mathrm{C}$. A more detailed description of manufacturing is given in [14].

Table 1. Chemical composition of the powder (wt.\%), used for Co-Selective Laser Sintering (Co-SLS) and Co-Powder Injection Molding (Co-PIM) manufacturing.

\begin{tabular}{ccccccccc}
\hline & Co & Cr & Mo & W & Si & Fe & Mn & C \\
\hline SLS & 63.8 & 24.7 & 5.1 & 5.4 & 1.0 & $<0.5$ & $<0.1$ & $<0.05$ \\
PIM & 64.9 & 27.0 & 5.3 & $<0.2$ & $<1.0$ & $<0.75$ & $<1$ & $<0.05$ \\
\hline
\end{tabular}

Tribological tests were performed on a CSM tribometer (CSM Instruments, Peseux, Switzerland), using the "ball on disk" method based on the methodology presented in ASTM G99-95A [15] and ISO/TS 14569-2: 2001 [16]. During wear testing, both samples were rotated and kept in constant contact with the counter-sample in the form of a $6 \mathrm{~mm}$ diameter $\mathrm{Al}_{2} \mathrm{O}_{3}$ ball (Gewa, Zabrze, Poland). The experiment was carried out in distilled water at $37 \pm 1^{\circ} \mathrm{C}$. The normal force applied by weight 
was $10 \mathrm{~N}$, the relative sliding velocity was kept constant at $10 \mathrm{~mm} / \mathrm{s}$, the diameter of the track along which the sample was moving was $3 \mathrm{~mm}$, and the total sliding distance was $100 \mathrm{~m}$.

The X-ray diffraction (XRD) measurements were performed with the Bragg-Brentano camera geometry using an X'Pert Philips diffractometer with a generator voltage of $40 \mathrm{kV}$ (Co-K $\alpha$ radiation). The relative amounts of $\gamma$ and $\varepsilon$ phases were estimated by measuring the integrated intensities of the principal peaks (Equation (1)) [6]:

$$
\% \gamma \text { phase }=\frac{\mathrm{I}_{(200) \gamma}}{\mathrm{I}_{(200) \gamma}+0.45 \mathrm{I}_{(101) \varepsilon}} \times 100
$$

where $\mathrm{I}_{(200) \gamma}$ and $\mathrm{I}_{(101) \varepsilon}$ are the diffracted intensities by (200) $\gamma$ and (101) $\varepsilon$, respectively.

Microstructure and traces left after wear tests were investigated using a Zeiss Supra 35 field-emission Scanning Electron Microscope (SEM) (Carl Zeiss SMT, Oberkochen, Germany). For Transmission Electron Microscopy (TEM) observations, specimens were prepared by the conventional thinning procedure and by Focused Ion Beam (FIB) technique using the SEM/Ga-FIB Helios NanoLab ${ }^{\mathrm{TM}}$ 600i microscope (FEI, Hillsboro, OR, USA). Thin foils, after mechanical polishing, were finally thinned by an ion beam system (Gatan Inc., Pleasanton, CA, USA) using Ar ions at $3 \mathrm{kV}$. Final milling of lamellae was performed with the $1 \mathrm{keV}$ ion Ga beam. TEM was carried out using a S/TEM TITAN 80-300 microscope equipped with a CEOS probe aberration corrector (FEI Company, Hillsboro, OR, USA). STEM images were collected with a 24.5-mrad probe semi-angle. Detector ranges were 25 mrad (Bright Field (BF)) and 47-200 mrad (High Angle Angular Dark Field (HAADF)). Crystal Maker and Single Crystal software (CrystalMaker Software Limited, version 10.4.1, Oxfordshire, UK) were used to simulate the crystal structure and diffraction patterns.

\section{Results}

\subsection{Crystalline Structure and Microstructure of Co-SLS and Co-PIM}

The phase composition of the Co-SLS and Co-PIM is shown in Figure 1. The result of the XRD analysis confirms for both materials the presence of the equilibrium phase $\varepsilon$ and the metastable phase $\gamma$, but their shares are different. The $\gamma$ phase has a face-centered cubic (fcc) lattice with a nominal parameter $\mathrm{a}=0.3548 \mathrm{~nm}$ (COD ID: 96-900-8466, space group Fm-3m, space group number 225). The $\varepsilon$ phase has a hexagonal close-packed (hcp) lattice with nominal parameters a $=0.25071 \mathrm{~nm}$ and $c=0.40686 \mathrm{~nm}$ (COD ID: 96-900-8492, space group P63/mmc, space group number 194) [17]. For both samples, there are no clear reflections from other phases, especially from carbides and the $\sigma$ phase. Only an asymmetrical shape of peaks can indicate the presence of these precipitates. For the Co-SLS, the $\gamma$ phase is dominant. Based on Equation (1), the amount of the $\gamma$ phase can be estimated as $85.9 \%$. For Co-PIM, the relative amount of $\gamma$ is lower and is equal to $8.9 \%$.

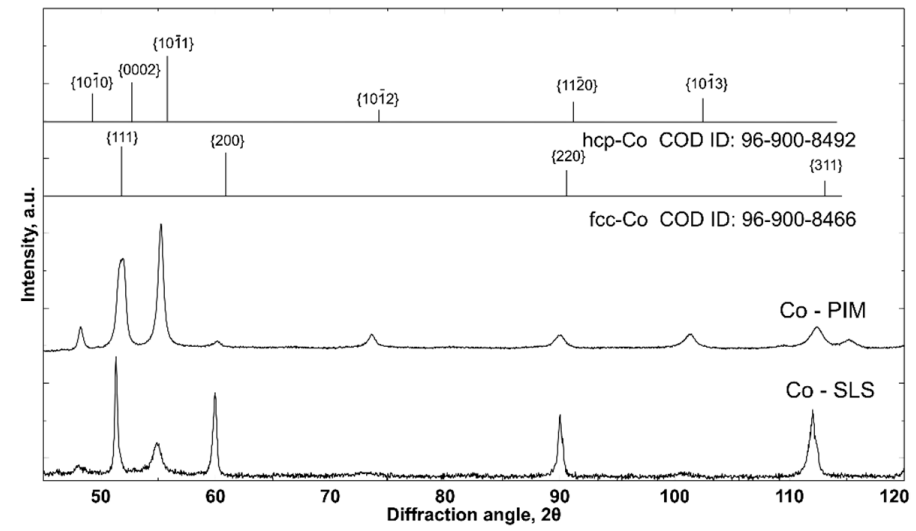

Figure 1. X-ray diffraction patterns of Co-Selective Laser Sintering (Co-SLM) and Co-Powder Injection Molding (Co-PIM) samples. 
Microstructures obtained by SLS and PIM techniques are showed in Figure 2. The alloy obtained by SLS is homogeneous, without porosity, and with large (micrometric) precipitates. As a result of preparation for SEM observation (a mixture of nitric acid and hydrochloric acid was used), grain boundaries were revealed. The grains are irregular and vary in size and shape, but their size can be estimated at about 10-50 $\mu \mathrm{m}$. The Co-PIM sample contains larger grains (approximately 20-60 $\mu \mathrm{m}$ ). Uniformly distributed precipitates, especially on grain boundaries, are visible. However, it is worth emphasizing that the material obtained by PIM was also homogeneous and that no large pores were observed.

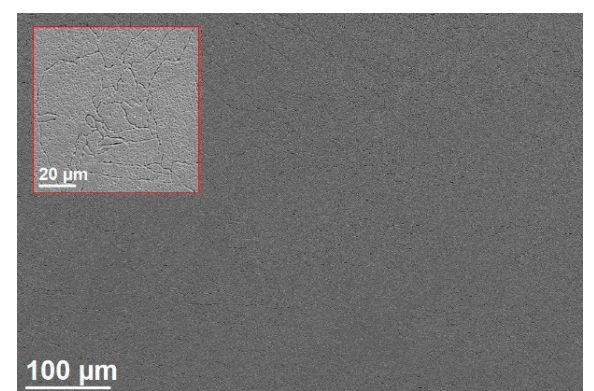

(a)

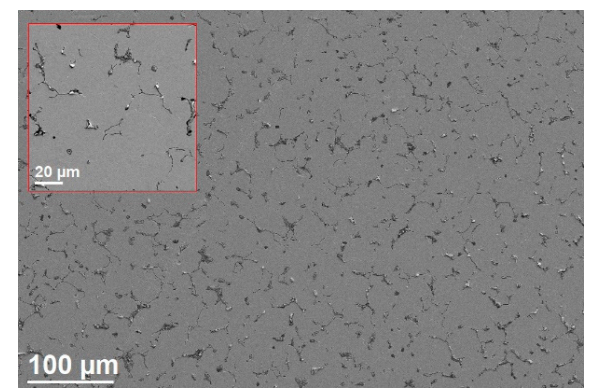

(b)

Figure 2. Scanning Electron Microscopy (SEM) images of the (a) Co-SLS and (b) Co-PIM samples.

The Co-SLS and Co-PIM structures were next analyzed by TEM. The substructure of Co-SLS was homogeneous, without visible pores and other large defects (Figure 3a), the presence of which was excluded earlier by SEM observations. Large precipitates of intermetallic phases (characteristic for cast alloy [18]) were still not detected here. The most characteristic feature of the Co-SLS structure is the presence of numerous stacking faults (SFs), arranged in two directions (indicated by red lines) and the presence of nanoprecipitates of two types (elongated and spherical), which are also evenly distributed (Figure 3b).

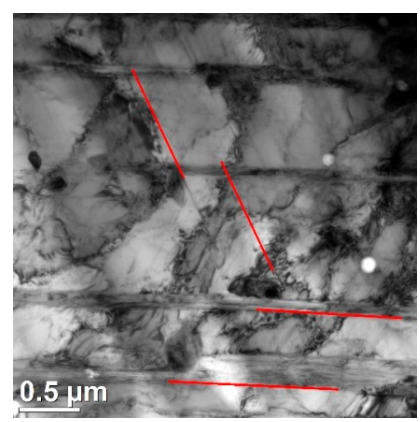

(a)

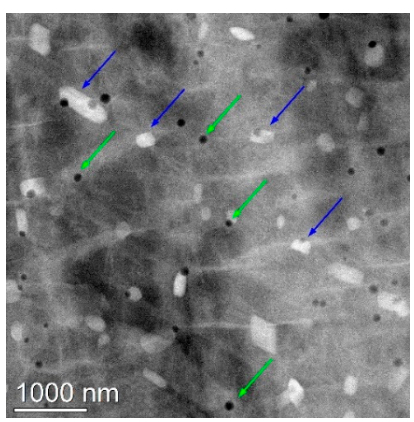

(b)

Figure 3. Co-SLS alloy sample structure. (a) Transmission Electron Microscopy Bright Field (TEM-BF) image, red lines indicate stacking faults (SF) and $\varepsilon$ phase bands in the $\gamma$ matrix; (b) Scanning Transmission Electron Microscopy High Angle Angular Dark Field (STEM-HAADF) image, blue arrows indicate nanoprecipitates of elongated shape, green arrows indicate spherical precipitates.

The Co-SLS matrix structure is shown in Figure 4, where intersecting $\varepsilon$ phase plates with a width of several to several dozen nanometers (Figure $4 a, c)$ and stacking faults (Figure $4 b$ ) are visible. For the [110] matrix orientation, the SFs intersect at $70.5^{\circ}$ (Figure $4 \mathrm{c}$ ). The phase composition of the matrix is also confirmed by the electron diffraction (Figure $4 \mathrm{~d}$ ). The results obtained show a pronounced tendency towards a deformation-induced phase transformation of the metastable $\gamma$ phase to the hexagonal low-temperature $\varepsilon$ phase, caused by a very low (and even negative) stacking fault energy of Co-based alloys [19]. A similar phenomenon—the TRansformation Induced Plasticity (TRIP) 
effect-has been described and is successfully used in steel design [20-22], enabling high strength properties while retaining high plasticity.

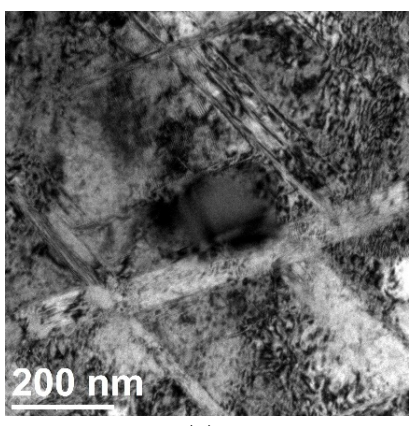

(a)

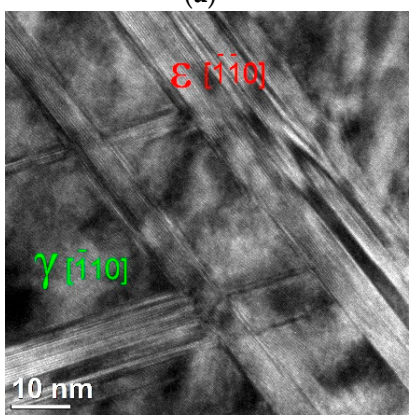

(c)

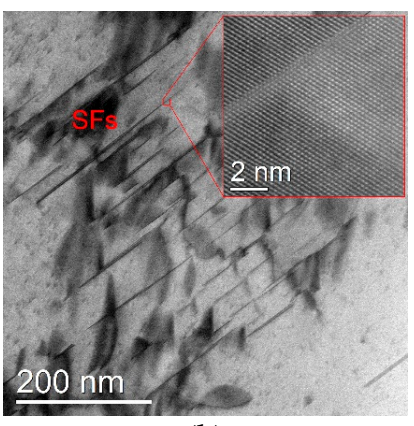

(b)

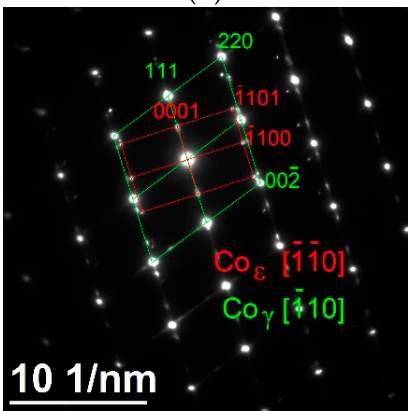

(d)

Figure 4. Co-SLS alloy matrix structure. (a) STEM-BF image; (b) slip bands, STEM-BF image; (c) $\varepsilon$ phase bands in the $\gamma$ matrix, TEM image; (d) Selected Area Electron Diffraction (SAED).

The irregular, elongated particles are evenly distributed, both at the grain boundaries and inside the grains (Figure 5a). Their size varies from 100 to $500 \mathrm{~nm}$. Spot EDS analysis showed a higher W, Si, and Mo content in particles than in the matrix (Figure 5b, Table 2). A higher concentration of W, Mo, and $\mathrm{Si}$ was also confirmed by the distribution of these elements (Figure 5c).

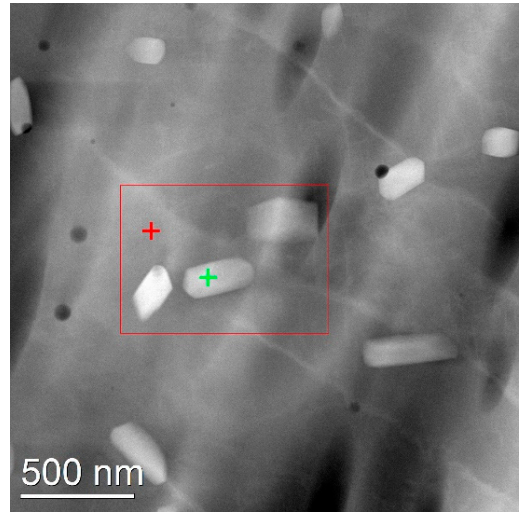

(a)

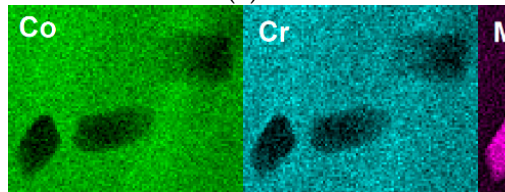

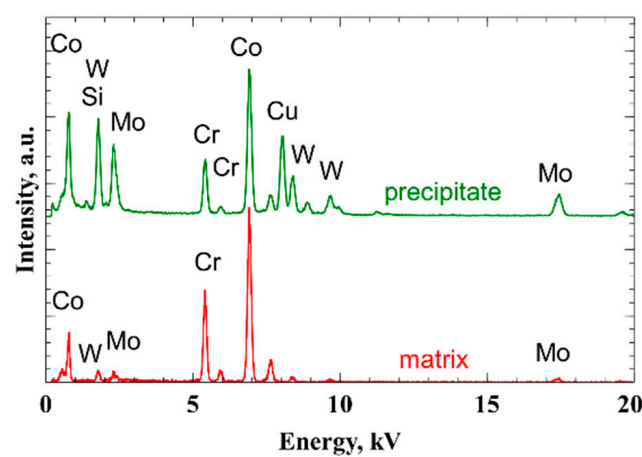

(b)

Mo Si

w

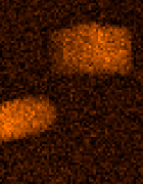

(c)

Figure 5. Chemical composition of the elongated shape precipitates. (a) STEM-HAADF image; (b) comparison of Energy Dispersive (EDS) spectra at the points indicated in (a); (c) maps of Co, Cr, $\mathrm{Mo}, \mathrm{Si}$, and $\mathrm{W}$ distribution in the area marked in (a). 
Table 2. Experimental results (wt.\%) of STEM-EDS analysis at the points indicated in Figure 4a.

\begin{tabular}{cccccc}
\hline Element & Co & Cr & Mo & Si & W \\
\hline Matrix & $65.9 \pm 0.6$ & $24.1 \pm 0.4$ & $4.6 \pm 0.3$ & $1.2 \pm 0.1$ & $4.2 \pm 0.2$ \\
Elongated precipitate & $41.1 \pm 1.0$ & $11.9 \pm 0.5$ & $21.5 \pm 1.3$ & $3.9 \pm 0.6$ & $21.6 \pm 1.1$ \\
Spherical precipitate & $62.2 \pm 0.7$ & $24.0 \pm 0.4$ & $4.1 \pm 0.4$ & $6.8 \pm 0.3$ & $2.9 \pm 0.2$ \\
\hline
\end{tabular}

Earlier studies $[23,24]$ indicated that the observed elongated particles have an hcp structure, with lattice parameters $\mathrm{a}=0.4734 \pm 0.0002 \mathrm{~nm}$ and $\mathrm{c}=0.7661 \pm 0.0003 \mathrm{~nm}$ and a composition resembling $\mathrm{Co}_{3}(\mathrm{Mo}, \mathrm{W})_{2} \mathrm{Si}$, with possible interchange of $\mathrm{Mo}$ and $\mathrm{W}$ atoms in the crystallographic lattice (space group P63/mmc, space group number 194). Selected Area Electron Diffraction (SAED) obtained for three differently oriented precipitates (Figure $6 \mathrm{a}-\mathrm{c}$ ) confirm this statement. $\mathrm{Co}_{3} \mathrm{~W}_{2} \mathrm{Si}$ is the $\mathrm{MgZn}_{2}$-type Laves phase. Other examples of such structures are $\mathrm{W}_{2} \mathrm{Ni}_{3} \mathrm{Si}, \mathrm{Ti}_{2} \mathrm{Ni}_{3} \mathrm{Si}_{1} \mathrm{Mo}_{2} \mathrm{Ni}_{3} \mathrm{Si}$, and $\mathrm{Co}_{3} \mathrm{Mo}_{2} \mathrm{Si}[3,4,6,19,25,26]$. These materials are known for their high hardness and dominant covalent nature of bonds, which makes them attractive in applications requiring high wear resistance $[27,28]$. The results of STEM imaging also showed that these hard precipitates in the Co-SLS can be deformed. Slip bands (marked with red arrows) are visible in Figure 7a. It confirms that the precipitates can, at least to some extent, change their shape before they break out. The second factor positively influencing the mechanical properties of the examined alloy is the presence of a cobalt matrix with the dominant share of the $\gamma$ phase. Cobalt is soft, and there are even more slip systems in the $\gamma$ phase than in the $\varepsilon$ phase. Figure $7 \mathrm{~b}$ confirms deformation of the matrix near the boundary of the hard precipitate.

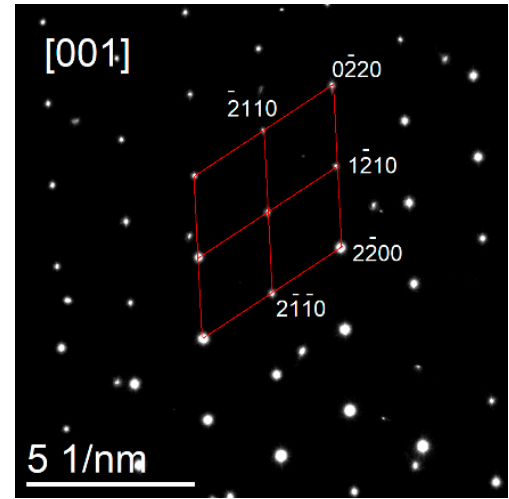

(a)

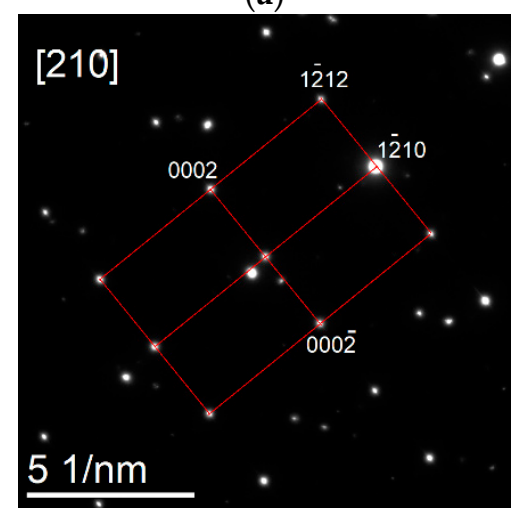

(c)

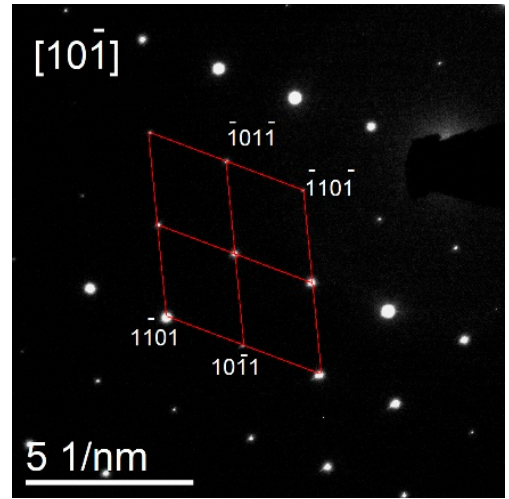

(b)

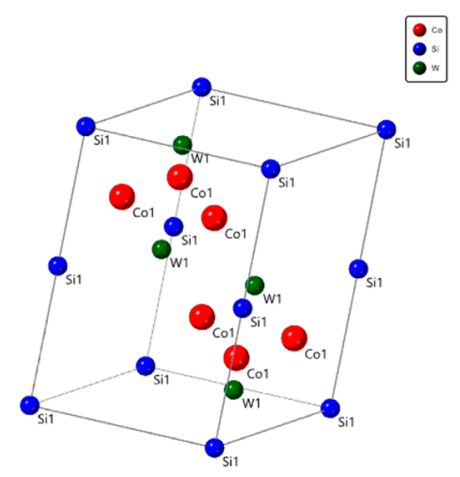

(d)

Figure 6. SAED electron diffraction of $\mathrm{Co} 3(\mathrm{Mo}, \mathrm{W}) 2 \mathrm{Si}$ in the direction (a) [001]; (b) [10-1]; and (c) [210]. (d) Model of Co3W2Si unit cell. 


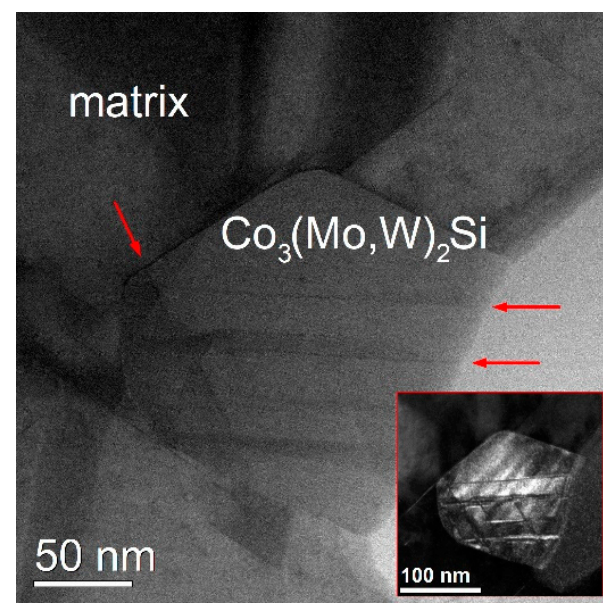

(a)

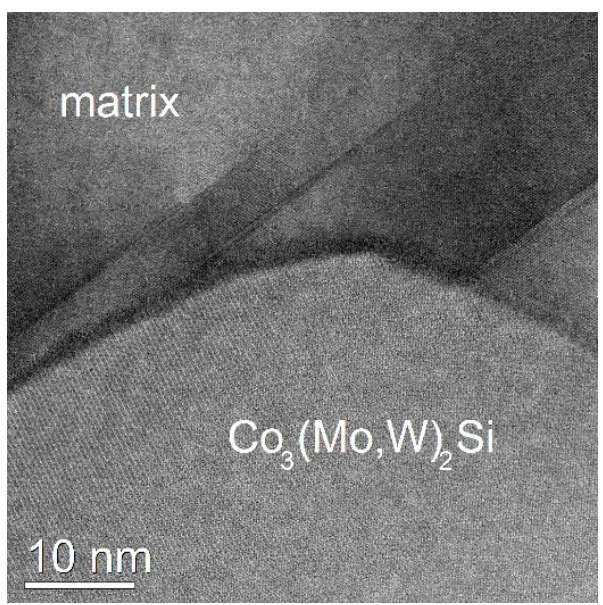

(b)

Figure 7. (a) STEM-HAADF image of $\mathrm{Co}_{3}(\mathrm{Mo}, \mathrm{W})_{2} \mathrm{Si}$ precipitate with slip bands marked with arrows (the insert contains the DF image); (b) high-resolution (HR) STEM-HAADF image of the boundary between precipitate and matrix.

The observed precipitates of the second type are spherical. These precipitates are smaller, homogenous in size (50-100 nm), and evenly distributed. In HAADF images (Figures 3b and 5a) they are almost black, which could indicate empty spaces (pores). When using a larger magnification (Figure 8a), the presence of nanometric atomic clusters (with a diameter of approximately $2-5 \mathrm{~nm}$ ) is observed. Chemical composition analysis, especially profile analysis (Figure 8b), confirms the increase (relative to the matrix) of $\mathrm{Si}$ concentration. It is worth emphasizing that this increase is statistically significant, but limited (in Figure 8b, to improve the readability of the figure, the intensity of the characteristic X-ray from $\mathrm{Si}$ has been increased six times). Figure $8 \mathrm{c}$ shows the HRTEM boundary between the spherical precipitate and the matrix. The figure also includes the Fast Fourier Transform (FFT) calculated for the matrix (upper) and precipitate (lower) part, respectively. Reflections are stronger on the first of them, which indicates a strongly crystalline matrix structure. In the case of the second FFT, individual reflections are visible and only in positions obtained for the matrix. The crystal structure is not visible in the precipitate. This can be interpreted that the analyzed precipitates have an amorphous structure (the weakened diffraction signal comes from the matrix material that is above/below the precipitate). The second, more convincing explanation is that these pores are a residue from silicon releases. Si was present in the CobaltChrome SP2 powder and evaporated during the remelting by laser. This is indicated by the spherical shape of the observed nanostructure and by the presence of small clusters of silicon atoms, visible in Figure 8a. Si precipitates are usually considered unfavorable in composites due to the risk of their uncontrolled growth. This does not apply to precipitates of such limited sizes $(<100 \mathrm{~nm})$ as in the described case, as well as to amorphous precipitates. An additional confirmation is the appearance of slip bands, visible in Figure 8d. They occur only in the matrix, and the presence of precipitates does not affect their behavior.

Four examples of precipitates in the Co-PIM sample are shown in Figure 9a. Based on the results of the EDS analysis (Figure 9b,c; Table 3), we can confirm the presence of both carbides and $\sigma$ phase. Point A in Figure 9 indicates the carbide (high Cr content), B indicates the $\sigma$ phase (Cr and Co in a similar amount), while $\mathrm{C}$ is the matrix (Co dominates). Figure 9 also shows the transformation of carbide into a brittle intermetallic $\sigma\left(\mathrm{Co}_{7} \mathrm{Cr}_{8}\right)$ phase. The presence of the $\sigma$ phase has been confirmed by SAED from the area marked in Figure 10. The $\sigma$ phase has a tetragonal lattice with a nominal parameter $a=0.8810 \mathrm{~nm}$ and $b=0.4560 \mathrm{~nm}$ (COD ID: 98-010-2316, space group P42/mnm, space group number 136) [29]. 


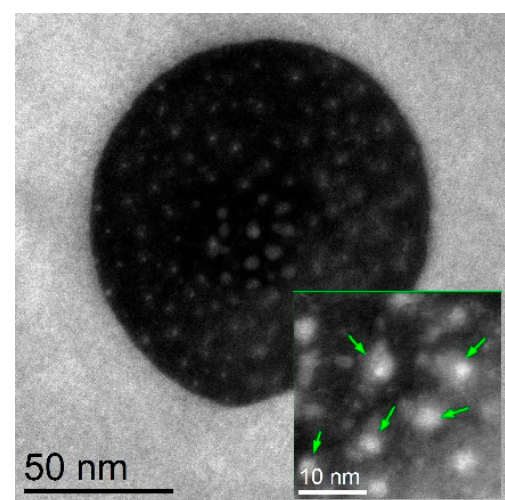

(a)

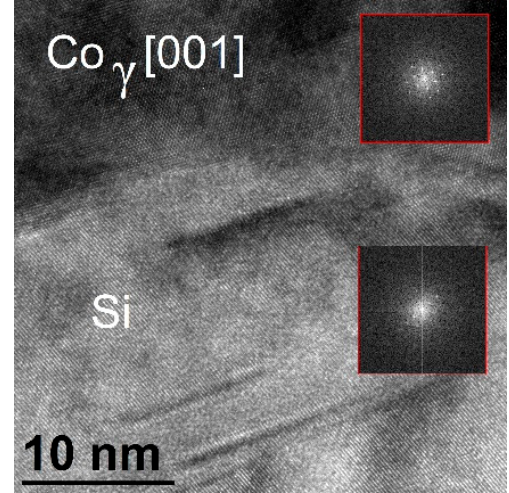

(c)

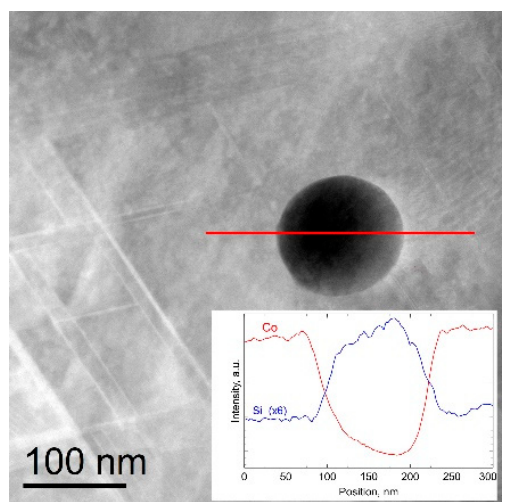

(b)

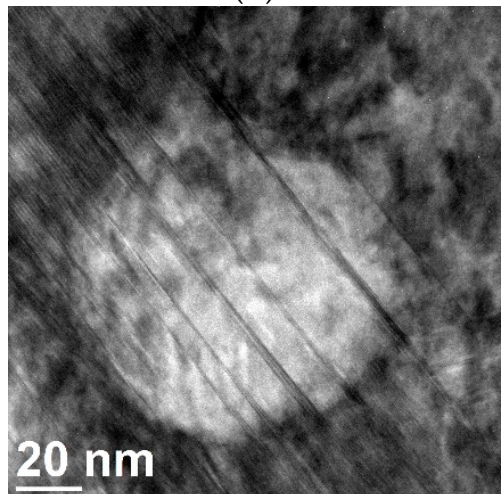

(d)

Figure 8. (a) STEM-HAADF image of Si-containing precipitation, the inset shows an enlargement with visible clusters of Si atoms, indicated by green arrows; (b) profile analysis of Co and Si exchanges; (c) STEM-BF image of the boundary between precipitate and matrix; (d) STEM-BF image of strongly deformed matrix with Si precipitate.

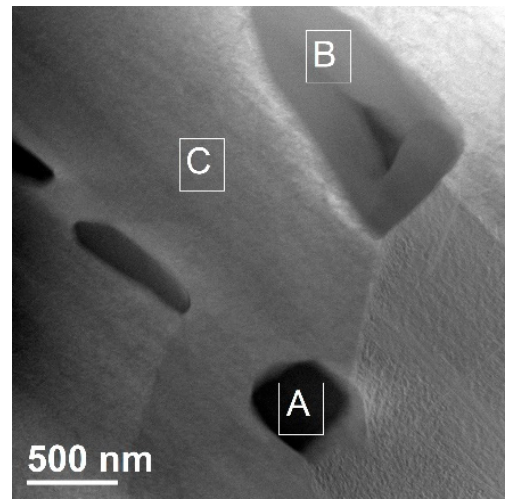

(a)

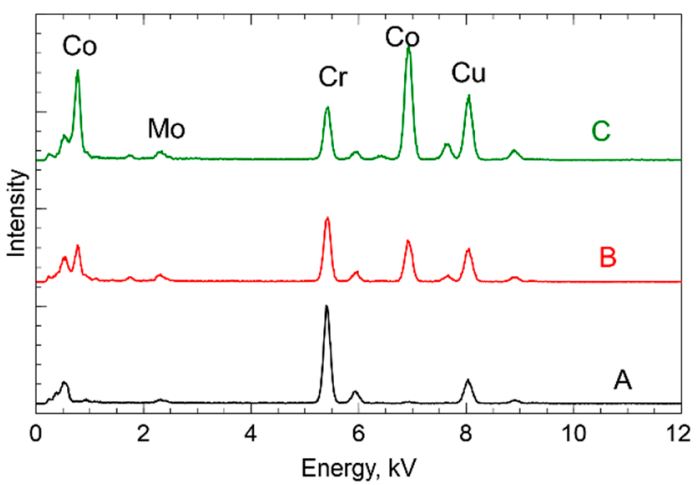

(b)

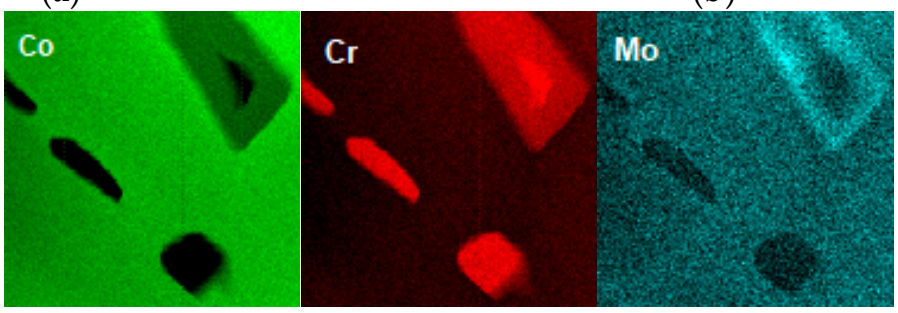

(c)

Figure 9. Chemical composition of the precipitates in the Co-PIM sample. (a) STEM-HAADF image; (b) comparison of EDS spectra at the points indicated in (a); (c) maps of $\mathrm{Co}, \mathrm{Cr}$, and Mo distribution in the area marked in (a). 
Table 3. Experimental results (wt.\%) of STEM-EDX analysis at the points indicated in Figure 9a. n.d. = not determined.

\begin{tabular}{cccccc}
\hline Element & Co & Cr & Mo & C & Si \\
\hline A & $2.0 \pm 0.1$ & $87.4 \pm 1.0$ & $10.6 \pm 0.4$ & n. d. & 0 \\
B & $40.4 \pm 0.5$ & $50.1 \pm 0.5$ & $7.9 \pm 0.3$ & n. d. & $1.6 \pm 0.1$ \\
C & $68.2 \pm 0.5$ & $26.6 \pm 0.3$ & $5.2 \pm 0.2$ & n. d. & 0 \\
\hline
\end{tabular}

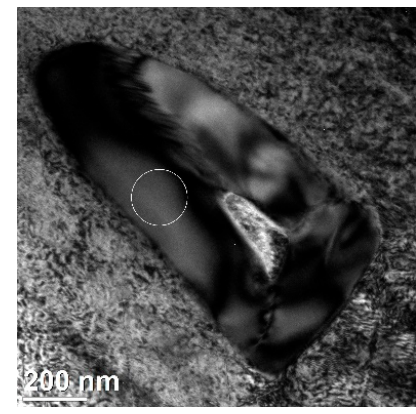

(a)

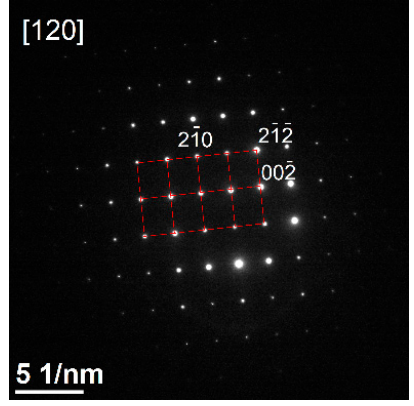

(b)

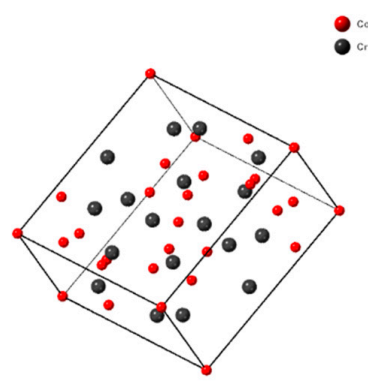

(c)

Figure 10. TEM image of selected precipitate in the Co-PIM sample (a). SAED electron diffraction of $\sigma$ phase $\left(\mathrm{Co}_{7} \mathrm{Cr}_{8}\right)$ in [120] the direction (b). Model of $\mathrm{Co}_{7} \mathrm{Cr}_{8}$ unit cell (c).

\subsection{Wear Resistance of Co-SLS and Co-PIM}

Figure 11 shows a comparison of friction coefficient changes during ball-on-disk wear testing for the Co-SLS and Co-PIM samples. The friction coefficient of the Co-SLS sample remained constant (approximately 0.4) throughout the measurement. In the first part of the test (up to $60 \mathrm{~m}$ ), the friction coefficient of the PIM sample was about 0.6 , and then increased to 0.8 . The worn surfaces were then examined with SEM (Figure 12). In the case of the SLS sample, the cavities are small, which confirms the high wear resistance of the SLS alloy. In the Co-PIM sample, obvious abrasive wear is observed, which brought out a large volume of material from the surface, causing the formation of many pits on the surface.

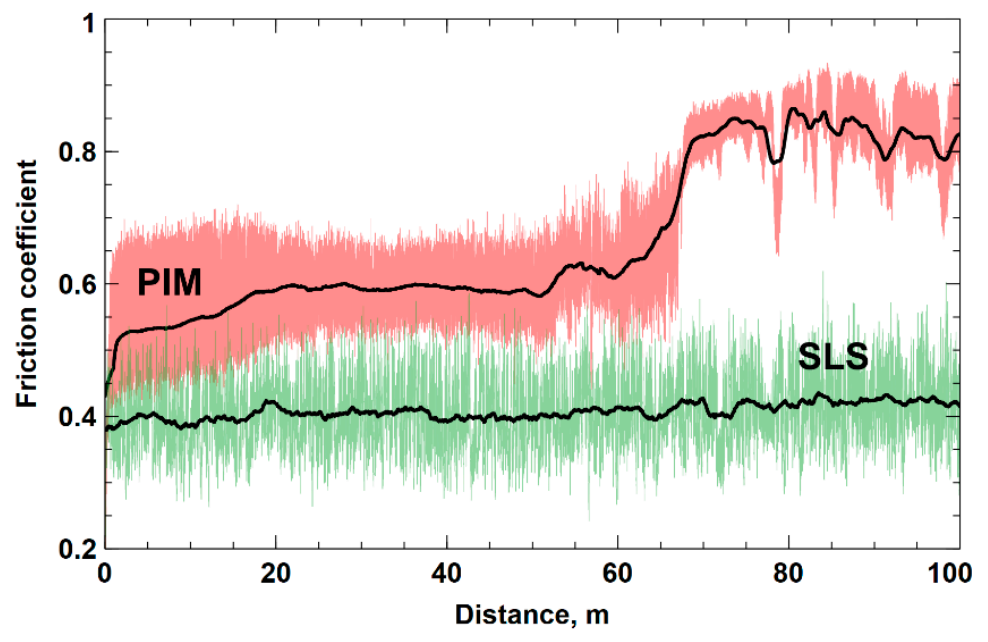

Figure 11. The friction coefficient during ball-on-disk wear testing. 


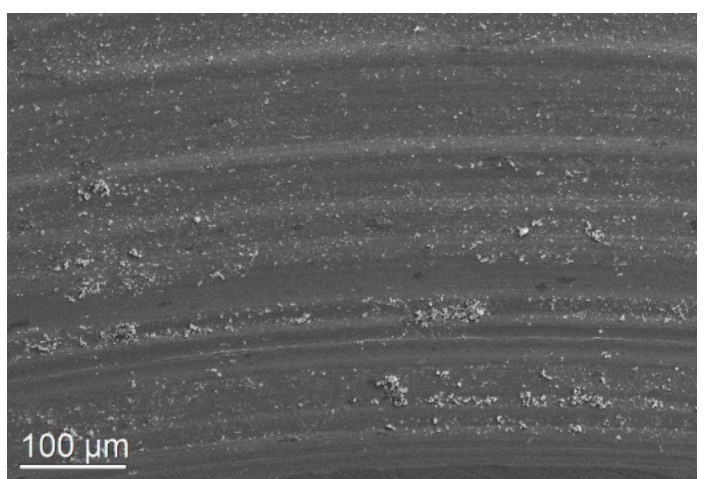

(a)

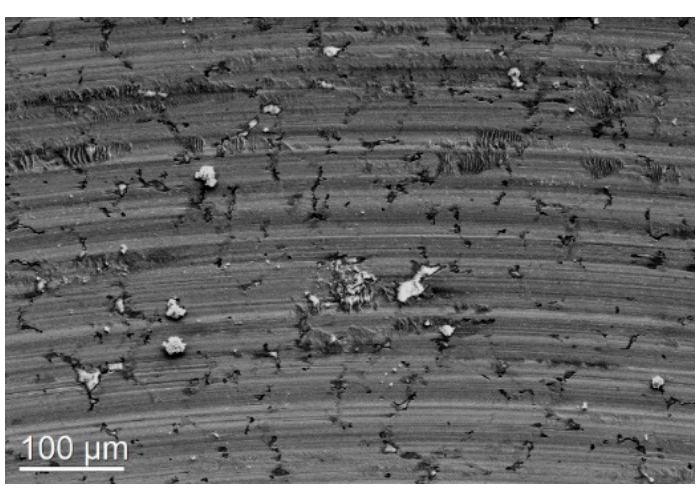

(b)

Figure 12. SEM images of wear scars of the (a) Co-SLS and (b) Co-PIM samples.

\section{Discussion}

Excellent wear resistance is one of the characteristics of $\mathrm{Co}-\mathrm{Cr}$ alloys. Additive manufacturing for metals and powder injection molding have recently received much attention as techniques for producing complex three-dimensional structures with excellent wear resistance from precursor powders. Our research results make it possible to compare the structure and abrasive wear of materials made with these techniques.

Differences for materials obtained from powders using SLS and PIM were visible during wear resistance measurements. The friction coefficient of the Co-SLS sample had a lower value and remained constant throughout the measurement. For the PIM sample, the value of this coefficient was higher from the beginning and increased in the second half of the test. It is known that mechanical and tribological properties of Co-based alloys strongly depend on their microstructure [30-32]. For example, friction coefficient is mainly influenced by microstructure, and the roughness impact is less important [33]. The use of electron microscopy and XRD allowed us to show that Co-SLS and Co-PIM have different structures and to link these differences with observed wear behavior.

Both materials are homogeneous, compact, and without porosity. The grain size is limited in both cases. A smaller grain size leads to a higher yield strength for the alloy, according to the Hall-Petch equation. Smaller grain sizes indicate the presence of more grain boundaries per unit area. Such boundaries act as impeding points to dislocation propagation; as a result, greater applied stress is needed for the dislocation propagation. However, the main factor determining wear resistance of CoCrMo alloys is the carbon amount, the homogeneity of the carbide distribution, and the presence of the hcp crystal structure [34-36].

The phase composition and amount of the precipitates in the tested materials result from the chemical composition and from the manufacturing process. Powders used for both techniques included a low content of carbon $(<0.05 \%)$. Most studies have suggested that a high carbon content in CoCrMo alloys improves the wear properties [30,37], resulting in excellent wear [38,39]. The presence of carbides affects the wear due to the hardness and the good coherency with the surrounding matrix, acting as a protective barrier against matrix delamination [30]. The small, evenly distributed carbides (especially on the surface) and the fine grain size have proven to be significantly beneficial for wear performance. The results of earlier studies do not indicate the improvement in wear behavior of Co-based alloys with low carbon content $[38,39]$.

Better wear resistance of Co-SLS, however, does not result from the presence of carbides. Their role was taken over by hard and evenly distributed $\mathrm{Co}_{3}(\mathrm{Mo}, \mathrm{W})_{2} \mathrm{Si}$ nanoprecipitates. The carbides were found in the Co-PIM sample, as a result of uncomplete polymer degradation. Their presence should be considered undesirable, primarily due to the limited control and the risk of transformation into a brittle $\sigma$ phase.

A significant difference between the samples' structure concerns the phase composition of the matrix. As expected, the hcp $\varepsilon$ phase is dominant in the matrix of the structure fabricated by PIM. 
The fcc $\gamma$ phase is the main matrix component of the SLS sample, what can be explained by the conditions of its production process. The critical value of thermal treatment for Co-based alloys, promoting martensitic transformation $\gamma \rightarrow \varepsilon$, is $970{ }^{\circ} \mathrm{C}$. To a lesser extent, the rate of martensitic transformation depends on the time of thermal treatment, as demonstrated by Zhang [40]. Therefore, the high proportion of the $\gamma$ phase in Co-SLS can be explained by the high cooling rate characteristic of SLS [1,2] and low temperature of heat treatment $\left(750^{\circ} \mathrm{C}\right)$. Alloys containing the $\varepsilon$ phase (hcp) have lower wear friction and wear volume losses than alloys with a higher share of the $\gamma$ (fcc) phase $[1,31,32]$. This effect is associated with few slip systems in the hcp structure and more difficult plastic deformation, which in turn avoids debris formation and results in better wear resistance. The results presented in [32] indicated that an alloy with an almost fully complete hcp structure exhibits a lower wear loss compared to an fcc structure. However, the high hardness of the carbides and/or other intermetallic precipitates could cause abrasive wear damage, when they are pulled out and fractured from the matrix [31]. Large precipitates are usually weakly bonded with the matrix. During wear resistance measurements they can be detached, with abrasive wear mechanism taking place. Large precipitates act as abrasives and reduce the alloy's wear resistance [32]. This was the case of Co-PIM. Abrasive wear was caused by precipitates such as the $\sigma$ phase and/or carbides, contained in the $\varepsilon$ matrix. For the Co-SLS sample, these negative factors were limited. Intermetallic precipitates strengthen the alloy, but to some extent they can be deformed, which reduces the probability of pulling them out of the matrix. An equally important factor is the possibility of matrix deformation near the precipitates. Because the precipitates are of limited size and are uniformly distributed in the matrix, the volume of torn-out material is also smaller. Moreover, the $\varepsilon$-martensite, formed by the strain-induced martensitic transformation through plastic straining during the sliding of the pin on the disk, decreases the wear rate [41].

\section{Conclusions}

New dynamically developing production techniques, for example, Selective Laser Sintering (SLS) and Powder Injection Molding (PIM), make it possible to produce homogeneous, compact, and non-porous Co-based alloys with low carbon content. An additional advantage of using these techniques is the ability to produce details of complex shapes. By combining the characteristic features of the matrix and the reinforcing phase, the SLS technique gains an additional advantage-high resistance to abrasive wear. To effectively use PIM for the production of Co-based alloy components, characterized by the required abrasive wear, the carbon content that remains as a result of incomplete polymer degradation must be controlled. Overcoming this barrier will expand the range of PIM applications.

Author Contributions: Conceptualization, A.Z., G.M. and M.P.; Investigation, K.M., W.P. and G.M.; Methodology, A.Z., K.M. and W.P.; Project administration, A.Z.; Writing—original draft, M.P.; Writing—review \& editing, A.Z., K.M., G.M. and W.P. All authors have read and agreed to the published version of the manuscript.

Funding: This research was funded by the National Center of Science [Grant No. 2018/02/X/ST8/01839].

Conflicts of Interest: The authors declare no conflict of interest.

\section{References}

1. Saldívar García, A.D.J.; Medrano, A.M.; Salinas Rodríguez, A. Formation of hcp martensite during the isothermal aging of an fcc Co-27Cr-5Mo-0.05C orthopedic implant alloy. Metall. Mater. Trans. A Phys. Metall. Mater. Sci. 1999, 30, 1177-1184. [CrossRef]

2. Lopez, H.F. Alloy developments in biomedical co-base alloys for HIP implant applications. Mater. Sci. Forum 2013, 736, 133-146.

3. Yamanaka, K.; Mori, M.; Kurosu, S.; Matsumoto, H.; Chiba, A. Ultrafine grain refinement of biomedical Co-29Cr-6Mo alloy during conventional hot-compression deformation. Metall. Mater. Trans. A Phys. Metall. Mater. Sci. 2009, 40, 1980-1994. [CrossRef]

4. Talonen, J.; Hänninen, H. Formation of shear bands and strain-induced martensite during plastic deformation of metastable austenitic stainless steels. Acta Mater. 2007, 55, 6108-6118. [CrossRef] 
5. Wei, W.; Zhou, Y.; Liu, W.; Li, N.; Yan, J.; Li, H. Microstructural Characterization, Mechanical Properties, and Corrosion Resistance of Dental Co-Cr-Mo-W Alloys Manufactured by Selective Laser Melting. J. Mater. Eng. Perform. 2018, 27, 5312-5320. [CrossRef]

6. Karaali, A.; Mirouh, K.; Hamamda, S.; Guiraldenq, P. Microstructural study of tungsten influence on Co-Cr alloys. Mater. Sci. Eng. A 2005, 390, 255-259. [CrossRef]

7. Marchese, G.; Garmendia Colera, X.; Calignano, F.; Lorusso, M.; Biamino, S.; Minetola, P.; Manfredi, D. Characterization and Comparison of Inconel 625 Processed by Selective Laser Melting and Laser Metal Deposition. Adv. Eng. Mater. 2017, 19, 1600635. [CrossRef]

8. Mindt, H.W.; Desmaison, O.; Megahed, M.; Peralta, A.; Neumann, J. Modeling of Powder Bed Manufacturing Defects. J. Mater. Eng. Perform. 2018, 27, 32-43. [CrossRef]

9. Kruth, J.P.; Mercelis, P.; Van Vaerenbergh, J.; Froyen, L.; Rombouts, M. Binding mechanisms in selective laser sintering and selective laser melting. Rapid Prototyp. J. 2005, 11, 26-36. [CrossRef]

10. Ziębowicz, A.; Woźniak, A.; Ziębowicz, B. The influence of technology on the physicochemical and electrochemical properties of the prosthetic materials. In Proceedings of the Advances in Intelligent Systems and Computing, Katowice, Poland, 18-20 October 2018; Springer: Cham, Switzerland; Volume 623, pp. 349-357.

11. Harris, I.D. A Transformational Advanced Manufacturing Technology. Adv. Mater. Processes 2012, 25.

12. German, R.M. Wear applications offer further growth for PIM. Met. Powder Rep. 1999, 54, 24-28. [CrossRef]

13. Wahi, A.; Muhamad, N.; Sulong, A.B.; Ahmad, R.N. Effect of Sintering Temperature on Density, Hardness and Strength of MIM Co30Cr6Mo Biomedical Alloy. J. Jpn. Soc. Powder Powder Metall. 2016, 63, 434-437. [CrossRef]

14. Matula, G.; Tomiczek, B.; Król, M.; Szatkowska, A.; Sotomayor, M.E. Application of thermal analysis in the selection of polymer components used as a binder for metal injection moulding of $\mathrm{Co}-\mathrm{Cr}-\mathrm{Mo}$ alloy powder. J. Therm. Anal. Calorim. 2018, 134, 391-399. [CrossRef]

15. ASTM G99_95a Test Method for Wear Testing with a Pin-On-Disk Apparatus; ASTM International: West Conshohocken, PA, USA, 2000.

16. ISO/TS 14569-2:2001. Dental Materials_Guidance on Testing of Wear_Part 2: Wear by Two-And/or Three Body Contact; ISO: Geneva, Switzerland, 2001.

17. Wyckoff, R.W.G. Cubic Closest Packed, ccp, Structure. In Crystal Structures, 2nd ed.; Interscience Publishers: New York, NY, USA, 1963; pp. 7-83.

18. Zhou, Y.; Wei, W.; Yan, J.; Liu, W.; Li, N.; Li, H.; Xu, S. Microstructures and metal-ceramic bond properties of Co-Cr biomedical alloys fabricated by selective laser melting and casting. Mater. Sci. Eng. A 2019, 759, 594-602. [CrossRef]

19. Weissensteiner, I.; Petersmann, M.; Antretter, T.; Clemens, H.; Weißensteiner, I.; Erdely, P.; Stark, A.; Maier-Kiener, V. Deformation-induced phase transformation in a Co-Cr-W-Mo alloy studied by high-energy X-ray diffraction during in-situ compression tests. Acta Mater. 2018, 164, 272-282. [CrossRef]

20. Frommeyer, G.; Métallurgie, O.G.-R. High strength TRIP/TWIP and superplastic steels: Development, properties, application. Rev. Métallurgie 1998, 95, 1299-1310. [CrossRef]

21. Zaefferer, S.; Ohlert, J.; Bleck, W. A study of microstructure, transformation mechanisms and correlation between microstructure and mechanical properties of a low alloyed TRIP steel. Acta Mater. 2004, 52, 2765-2778. [CrossRef]

22. Grässel, O.; Krüger, L.; Frommeyer, G.; Meyer, L.W. High strength Fe-Mn-(Al, Si) TRIP/TWIP steels development-Properties-Application. Int. J. Plast. 2000, 16, 1391-1409. [CrossRef]

23. Mengucci, P.; Barucca, G.; Gatto, A.; Bassoli, E.; Denti, L.; Fiori, F.; Czyrska-Filemonowicz, A. Effects of thermal treatments on microstructure and mechanical properties of a $\mathrm{Co}-\mathrm{Cr}-\mathrm{Mo}-\mathrm{W}$ biomedical alloy produced by laser sintering. J. Mech. Behav. Biomed. Mater. 2016, 60, 106-117. [CrossRef]

24. Santecchia, E.; Gatto, A.; Bassoli, E.; Denti, L.; Rutkowski, B.; Mengucci, P.; Barucca, G. Precipitates formation and evolution in a Co-based alloy produced by powder bed fusion. J. Alloys Compd. 2019, 797, 652-658. [CrossRef]

25. Yamanaka, K.; Mori, M.; Koizumi, Y.; Chiba, A. Local strain evolution due to athermal $\gamma \rightarrow \varepsilon$ martensitic transformation in biomedical CoCrMo alloys. J. Mech. Behav. Biomed. Mater. 2014, 32, 52-61. [CrossRef] [PubMed] 
26. Wang, H.; Luan, D.; Zhang, L.Y. Microstructure and wear resistance of laser melted W/W2Ni3Si metal silicides matrix in situ composites. Scr. Mater. 2003, 48, 1179-1184. [CrossRef]

27. Liu, Y.; Wang, H.W. Toughening and dry sliding wear resistance of Co3Mo2Si alloys. Wear 2013, 297, 952-957. [CrossRef]

28. Liu, Y.; Wang, H.M. Microstructure and wear property of laser-clad Co3Mo2Si/Coss wear resistant coatings. Surf. Coat. Technol. 2010, 205, 377-382. [CrossRef]

29. Dickins, G.J.; Douglas, A.M.B.; Taylor, W.H. The crystal structure of the Co-Cr $\sigma$ phase. Acta Crystallogr. 1956, 9, 297-303. [CrossRef]

30. Varano, R.; Bobyn, J.D.; Medley, J.B.; Yue, S. The effect of microstructure on the wear of cobalt-based alloys used in metal-on-metal hip implants. Proc. Inst. Mech. Eng. Part H J. Eng. Med. 2006, 220, 145-159. [CrossRef]

31. Chiba, A.; Kumagai, K.; Nomura, N.; Miyakawa, S. Pin-on-disk wear behavior in a like-on-like configuration in a biological environment of high carbon cast and low carbon forged Co-29Cr-6Mo alloys. Acta Mater. 2007, 55, 1309-1318. [CrossRef]

32. Saldívar-García, A.J.; López, H.F. Microstructural effects on the wear resistance of wrought and as-cast Co-Cr-Mo-C implant alloys. J. Biomed. Mater. Res. Part A 2005, 74, 269-274. [CrossRef]

33. Bedolla-Gil, Y.; Hernandez-Rodriguez, M.A.L. Tribological behavior of a heat-treated cobalt-based alloy. J. Mater. Eng. Perform. 2013, 22, 541-547. [CrossRef]

34. Yan, Y.; Neville, A.; Dowson, D. Tribo-corrosion properties of cobalt-based medical implant alloys in simulated biological environments. Wear 2007, 263, 1105-1111. [CrossRef]

35. Long, W.T. The clinical performance of metal-on-metal as an articulation surface in total hip replacement. Iowa Orthop. J. 2005, 25, 10-16. [PubMed]

36. Cawley, J.; Metcalf, J.E.P.; Jones, A.H.; Band, T.J.; Skupien, D.S. A tribological study of cobalt chromium molybdenum alloys used in metal-on-metal resurfacing hip arthroplasty. Wear 2003, 255, 999-1006. [CrossRef]

37. Tipper, J.L.; Firkins, P.J.; Ingham, E.; Fisher, J.; Stone, M.H.; Farrar, R. Quantitative analysis of the wear and wear debris from low and high carbon content cobalt chrome alloys used in metal on metal total hip replacements. J. Mater. Sci. Mater. Med. 1999, 10, 353-362. [CrossRef] [PubMed]

38. Dowson, D.; Hardaker, C.; Flett, M.; Isaac, G.H. A hip joint simulator study of the performance of metal-on-metal joints: Part I: The role of materials. J. Arthroplast. 2004, 19, 118-123. [CrossRef]

39. Scholes, S.C.; Unsworth, A. Pin-on-plate studies on the effect of rotation on the wear of metal-on-metal samples. J. Mater. Sci. Mater. Med. 2001, 12, 299-303. [CrossRef]

40. Zhang, M.; Yang, Y.; Song, C.; Bai, Y.; Xiao, Z. An investigation into the aging behavior of CoCrMo alloys fabricated by selective laser melting. J. Alloys Compd. 2018, 750, 878-886. [CrossRef]

41. Hassani, F.Z.; Ketabchi, M.; Bruschi, S.; Ghiotti, A. Effects of carbide precipitation on the microstructural and tribological properties of $\mathrm{Co}-\mathrm{Cr}-\mathrm{Mo}-\mathrm{C}$ medical implants after thermal treatment. J. Mater. Sci. 2016, 51, 4495-4508. [CrossRef]

(C) 2020 by the authors. Licensee MDPI, Basel, Switzerland. This article is an open access article distributed under the terms and conditions of the Creative Commons Attribution (CC BY) license (http://creativecommons.org/licenses/by/4.0/). 